\title{
ALTERNATIVAS ECONÔMICAS PARA A SOBREVIVÊN- CIA DAS MULHERES EM UMA CIDADE DE BAIXO IDH: O CASO DE GOIATINS (ESTADO DO TOCANTINS)'
}

\author{
Fernanda Pereira de Brito ${ }^{2}$ \\ Renata Rauta Petarly ${ }^{3}$ \\ Tatiane Marinho Vieira Tavares ${ }^{4}$
}

Resumo: A pesquisa desenvolvida procurou identificar e descrever as condições socioeconômicas de uma parcela das mulheres chefes de família residentes na cidade de Goiatins, que possui um Índice de Desenvolvimento Humano de 0,576, na região nordeste do Estado do Tocantins. Os resultados informam que as fontes de sobrevivência e sustento monetário das mulheres são compostas por 11 tipos de atividades remuneradas e quatro tipos de benefícios sociais, além de quatro atividades não monetárias e, que o tempo médio dedicado ao trabalho monetário e não monetário foi de aproximadamente cinco horas por dia.

Palavras-Chave: Economia Feminista, Trabalho das mulheres, Região Norte.

Abstract: The study developed aimed to identify and describe the socioeconomic conditions of a share of female head of families residing in the city of Goiatins, which has a Human Development Index of 0.576, in the northeastern region of the state of Tocantins. The results showed that women's sources of survival and monetary support are composed of 11 types of paid work, four types of social benefits, and four unpaid work activities. The average time spent on paid and unpaid work was approximately five hours a day. Keywords: Feminist Economics, Women's labor, North Region.

\section{Introdução}

Conforme as informações disponíveis no Atlas do Desenvolvimento Humano

\footnotetext{
1 O presente trabalho foi realizado com apoio da Coordenação de Pessoal de Nivel Superior- Brasil (CAPES). Agradecemos às mulheres de Goiatins-To, por aceitarem participar desta pesquisa. As autoras também são gratas à Benilson Pereira dos Santos, geógrafo e funcionário do Naturatins pela confecção do mapa de Goiatins.

2 E-mail: Mestre em Demandas Populares e Dinâmicas Regionais pelo Programa de Pós-Graduação em Demandas Populares e Dinâmicas Regionais (PPGdire) da Universidade Federal do Tocantins, bolsista CAPES no intervalo de 2017-2019: nanda_18brito@hotmail.com

3 Mestre em Extensão Rural pela Universidade Federal de Viçosa; docente do curso de Tecnologia em Gestão de Cooperativas na Universidade Federal do Tocantins; renatapetarly@uft.edu.br

4 Doutora em Geociências pela UNESP, docente do curso de Biologia e do Programa de Pós-Graduação em Demandas Populares e Dinâmicas Regionais (PPGdire) na Universidade Federal do Tocantins. E-mail: tatianetavares@uft. com.br
} 
no Brasil (2016), o municipio de Goiatins possui um Índice de Desenvolvimento Humano de 0,5. Tal índice o posiciona entre os últimos no ranking de municípios do Estado do Tocantins. Este dado reflete as condições socioeconômicas da população goiatinense, ao se considerar que $37,47 \%$ são extremamente pobres e $53,72 \%$ são pobres. Se a pobreza afeta $91,19 \%$ da população geral, de que maneira sobrevivem as mulheres desta cidade?

Considerando o exposto acima, o objetivo primário deste trabalho foi, por meio da teoria da economia feminista, identificar quais são as fontes de sobrevivência que garantem o sustento das mulheres de Goiatins (TO), incluindo a renda monetária e não monetária e a produção de bens e serviços gratuitos realizados por elas.

É necessário esclarecer que as fontes de sustento ou sobrevivência, aqui consideradas, estão além das de uma remuneração advinda de um trabalho formal ou informal e que abrange tudo aquilo que contribui para o sustento da vida, como a produção de objetos e alimentos para uso de si e daqueles que convivem com elas, o cultivo de plantas comestíveis e/ou medicinais, a coleta de frutos e a criação de pequenos animais.

Para melhor compreender a composição das alternativas de sobrevivência foi necessário identificar quais eram as ocupações às quais as mulheres se dedicavam e quanto tempo de sua rotina era destinada a essas ocupações e promover a classificação das ocupações em termos de trabalho formal e informal. Adicionalmente, foi possivel analisar de que forma as ocupações desempenhadas pelas mulheres impactavam no sustento de suas familias, pois foi utilizada aqui a abordagem da economia feminista para evidenciar as experiências econômicas das mulheres e para se compreender que aspectos eram responsáveis por suas autonomias econômicas ou não.

Para Barbosa (2007) o trabalho formal é caracterizado por aquele que é regulamentado pela lei ou por acordos coletivos que asseguram ao trabalhador os direitos trabalhistas mínimos de proteção. $\bigcirc$ trabalho informal seria aquele não regulamentado e/ou sem garantias dos direitos trabalhistas mínimos assegurados por lei, como, por exemplo, a licença-maternidade ou a aposentadoria; monetário e não monetário (BARBOSA, 2007).

trabalho é composto por um referencial teórico que contempla a teoria da divisão sexual do trabalho, a economia feminista e a autonomia econômica das mulheres. Essas teorias buscam elucidar questões relacionadas ao trabalho das mulheres, sejam eles monetários ou não monetários, produtivos ou reprodutivos, bem como de discussões sobre as maneiras de evidenciar o trabalho das mulheres no meio das pesquisas científicas e soluções para as desigualdades no mundo do trabalho entre homens e mulheres.

A contribuição desta pesquisa é a de tornar visiveis as experiências econômicas das mulheres de Goiatins (TO), sejam elas monetárias ou não, o tempo que 
destinam as ocupações no dia a dia, a contribuição que dão para suas famílias e suas necessidades socioeconômicas.

\section{Referencial teórico}

\section{A divisão sexual do trabalho}

A divisão sexual do trabalho diz respeito à forma como mulheres e homens, em determinadas sociedades, são destinados a algumas atividades de trabalho baseando-se em supostas características, capacidades e qualidades naturalmente correspondentes a um ou a outro sexo. Em tal forma de dividir as funções de trabalho, os homens são responsáveis pelo trabalho produtivo e as mulheres pelo trabalho reprodutivo. Além disso, os trabalhos desempenhados predominantemente pelos homens seriam mais valorizados do que os trabalhos realizados predominantemente por mulheres. Em outras palavras:

A divisão sexual do trabalho é a forma de divisão do trabalho social decorrente das
relações sociais de sexo; essa forma é historicamente adaptada a cada sociedade.
Tem por características a destinação prioritária dos homens à esfera produtiva e
das mulheres à esfera reprodutiva e, simultaneamente, a ocupação pelos homens
das funções de forte valor social agregador [...] (HIRATA, et. al., 2009, p. 67).

Conforme Hirata et. al. (2009) a divisão sexual do trabalho é uma maneira de separar determinadas tarefas como sendo femininas ou masculinas, isto é, às mulheres são destinados os trabalhos reprodutivos e aos homens os trabalhos produtivos; além desta separação são atribuídos diferentes valores para o que é trabalho masculino e trabalho feminino. Para Hirata e colaboradoras (2009) há dois princípios que organizam a divisão sexual do trabalho: o primeiro seria a separação, que distingue o que é naturalmente trabalho de homem e trabalho de mulher e o segundo seria a hierarquização, pelo qual um trabalho tem mais valor que o outro, no caso o trabalho produtivo dos homens.

A conjunção dos princípios mencionados tem colaborado demasiadamente para que o trabalho que as mulheres realizam seja visto como menos importante que o dos homens. Butto e colaboradoras (2014, p. 100) dizem que: "A ideia de que mulheres e homens nascem com capacidades distintas para realizar determinadas atividades é uma construção histórica que oculta o trabalho das mulheres e institui a noção de superioridade do trabalho masculino". As consequências da separação entre trabalho de homem e de mulher e da hierarquização de um sobre o outro, de acordo as autoras, são o de tornar o trabalho feminino invisivel e construir a ideia de que $\circ$ trabalho masculino é mais importante e por isto digno de visibilidade. 
Os homens são destinados prioritariamente às atividades vinculadas à esfera produtiva, enquanto as mulheres à esfera reprodutiva, e ao mesmo tempo em que há uma maior valorização do trabalho masculino e eles exercem as atividades de maior valor agregado. Essa formulação permite abordar a relação entre produção e reprodução, explica a simultaneidade das mulheres nos trabalhos produtivo e reprodutivo e sua exploração diferenciada no mundo produtivo e no trabalho assalariado (SABBATO et. al., 2009, p. 18).

Assim, fica evidente uma das desigualdades que afeta muito mais as mulheres dentro da divisão sexual do trabalho, pois ainda que sejam as responsáveis majoritárias pelas tarefas domésticas e de cuidados na esfera reprodutiva, elas trabalham também na esfera produtiva, de forma assalariada, na cidade e no campo, mas:

\begin{abstract}
A presença das mulheres no trabalho assalariado ou no campo não alterou em nada a responsabilidade quase exclusiva pelo trabalho doméstico e o cuidado. Para as mulheres a realização do trabalho doméstico e de cuidados coloca-se como parte de sua identidade primária, uma vez que a maternidade é considerada seu lugar principal (SABBATO et al., 2009, p. 18).
\end{abstract}

Observa-se que mesmo que as mulheres tenham rompido "parcialmente" com a mais clássica forma de divisão sexual do trabalho que pressupõe um homem provedor da família e uma mulher responsável pelo lar e pelos filhos, quando são inseridas na esfera produtiva do trabalho, elas permanecem reféns da desigualdade dentro de suas casas, pois as tarefas domésticas e de cuidados não remuneradas, para com os filhos, os idosos e as pessoas física ou mentalmente dependentes, são realizadas majoritariamente por elas, pois permanece sendo considerado como seu dever. Como diz Moreno (2013 p.62): "A desigualdade na divisão sexual do trabalho se manifesta, no âmbito doméstico, pela diferença do tempo gasto por mulheres e homens na realização do trabalho doméstico e de cuidados não remunerado". Assim o trabalho das mulheres na esfera pública ou privada, remunerado ou não, exibe peculiaridades:

Em uma sociedade patriarcal, estruturada por uma divisão sexual do trabalho desigual, olhar para os cuidados implica considerar as consequências que a sobrecarga de trabalho imposta às mulheres acarreta em diversos âmbitos. Um exemplo comum é o de que, devido às responsabilidades das mulheres com o cuidado dos filhos, elas procuram emprego em tempo parcial e com mais flexibilidade, elemen- 
tos que estão relacionados à informalidade e à precarização. [...] Por outro lado, o aumento da participação feminina no mercado de trabalho remunerado não foi acompanhado por uma reorganização do trabalho de cuidados capaz de alterar a desigualdade de sua realização por homens e mulheres (MORENO, 2013, p. 56).

A maneira como se lida com essas peculiaridades varia de acordo a classe social, pois: "aquelas que estão mais bem posicionadas no mercado de trabalho recorrem à serviços oferecidos pelo mercado ou à contratação de outras mulheres, aspectos que recriam desigualdades entre as próprias mulheres" (MORENO, 2013, p. 56). Acerca das mulheres mais pobres, Fontoura e Gonzalez (2009, p. 22) dizem que: "as mulheres mais pobres, cuja renda familiar per capita não ultrapassa meio salário mínimo (SM), são as que menos participam do mercado de trabalho e mais enfrentam o desemprego". Isto porque se dedicam muito mais aos trabalhos domésticos e de cuidados.

Segundo o Instituto Brasileiro de Geografia e Estatística - IBGE (2013), as mulheres gastam no Brasil, em média 20,8 horas semanais com o trabalho doméstico não remunerado, enquanto os homens gastam em média apenas 10 horas semanais. Nesta situação, as mulheres nem sequer chegam a trabalhar fora de casa ou acabam em trabalhos informais e precários que permitem uma maior flexibilidade em suas jornadas, embora lhe custem direitos. "Quanto mais alguém se dedica às tarefas domésticas e ao cuidado, menor sua condição de assumir as atividades de produção e de comercialização" (BUTTO et. al., 2014, p. 108). Quanto às mulheres que chegam ao mercado de trabalho, há ainda traços da divisão sexual do trabalho:

As mulheres estão concentradas nos empregos ditos "femininos" no sentido de que se baseiam em uma responsabilidade em relação a outrem. Elas ocupam maciçamente profissões que reproduzem, no universo profissional, as tarefas do serviço que assumem na família: cuidam de crianças, são auxiliares de enfermagem, enfermeiras, empregadas domésticas, faxineiras [...] e no serviço público, as mulheres gerenciam a logística do mesmo modo que asseguram a boa administração do lar (GUÉRIN, 2005, p. 40).

Outras profissões também são exercidas pelas mulheres, além daquelas mencionadas acima, mas o que se enfatiza é que os empregos que requerem cuidados e habilidades domésticas são majoritariamente ocupados por mulheres.

Segundo a Pesquisa Nacional por Amostra de Domicilios - PNAD (2015), por exemplo, os trabalhadores domésticos do Brasil eram compostos por um total de 6.423 trabalhadores domésticos, em números absolutos (1.000). Do total de trabaIhadores domésticos: 473 eram homens e quase metade deles com carteira assinada: 
213, e 5.951 eram mulheres, sendo apenas 1.909 delas com carteira assinada.

Por fim, na contramão dos dois princípios base da divisão sexual de separação e hierarquização há a economia feminista. A economia feminista é uma corrente teórica que busca remover da invisibilidade, por meio de estudos e análises teóricas, o trabalho não remunerado que as mulheres realizam na esfera privada e, ainda se presta a entender as particularidades do trabalho das mulheres na esfera pública, seja ele remunerado ou não. A seguir será apresentada a conceituação da economia feminista.

\title{
Economia feminista
}

A economia feminista é uma parte do pensamento econômico que segundo Quintela (2006, p. 13) surge na década de 70, no século XX: "Nesse período, cresceram as formulações críticas com novas abordagens para as ciências econômicas a partir do feminismo, questionando tanto a escola neoclássica como a marxista". De modo que a economia feminista é uma corrente teórica que se presta a construir uma visão diferente da visão androcêntrica, sendo esta, segundo Moreno (2013, p. 15) a: "[...] construção de noções e teorias que tomam a experiência dos homens como universal, ao ocultar e/ou desconsiderar as experiências das mulheres". Neste sentido, a economia feminista atua em outro viés:

\begin{abstract}
A economia feminista questiona o paradigma dominante e sua abordagem androcêntrica e contribui para dar visibilidade ao aporte econômico das mulheres. Já a economia dominante não só desconsidera, invisibiliza a contribuição econômica das mulheres, como oculta e desconheceaselaboraçõesteóricas dasfeministas(SABBATOet.al.,2009, p.14,15).
\end{abstract}

Trata-se, portanto, de construir uma visão econômica que contemple as muIheres e homens enquanto atores econômicos e ainda de resgatar e mostrar as experiências femininas que tradicionalmente ficam aquém das experiências masculinas quando as teorias e estudos da economia dominante são realizados. Pois, "no caso das atividades econômicas, trata-se não apenas de dizer onde estão as mulheres, mas de ir além e explicar e explicitar os motivos pelos quais suas atividades são ocultadas na teoria e mantidas desvalorizadas na prática, questionando-os" (MORENO, 2013, p. 13).

Seria construir conhecimentos para entender criticamente o papel da mulher na economia. É do interesse da economia feminista, todas as atividades econômicas realizadas pelas mulheres, sejam elas monetárias ou não, pois para a economia feminista existe uma interdependência entre a economia monetária e a economia não monetária e entre a esfera produtiva e reprodutiva. Para uma melhor compreensão, entende-se que é pelo ganho de um salário que a maioria das pessoas 
adquire bens e serviços no mercado para as suas necessidades, porém, é no interior dos lares que a outra parte desssas necessidades são saciadas por meio da realização do trabalho doméstico e de cuidados. Esse trabalho não pode ser comercializado totalmente por dois motivos. Primeiro: os salários das pessoas são insuficientes para comprar toda a parte comercializável do trabalho doméstico e de cuidados. Segundo: existem aspectos deste trabalho que são incomercializáveis devido às suas características subjetivas, o que inclui os afetos e as emoções que também são necessários para a vida humana (CARRASCO, 2012; MORENO 2013).

Sendo assim, tanto o trabalho mercantil quanto o doméstico e de cuidados, remunerados ou não, realizados pelas mulheres são objeto de estudo das economistas feministas, bem como outros fatores que afetem esses trabalhos:

A economia feminista tem se dedicado a estudar e construir elaborações em di-
versos campos, tais como a crítica conceitual e metodológica, o trabalho das mu-
Iheres (compreendendo o mercantil, doméstico e de cuidados), a globalização, os
orçamentos com sensibilidade de gênero [...] (SABBATO, et. al., 2009, p. 17).

Tais iniciativas da economia feminista têm contribuído para que as atividades econômicas desenvolvidas pelas mulheres deixem de ser tratadas como algo sem valor. Carrasco (2012, p. 36) considera neste sentido que "se tudo o que é feminino tem sido desvalorizado pelo patriarcado, isso não quer dizer que não tenha valor". E "[...], para desativar o patriarcado teríamos, primeiramente, que recuperar o valor do que é feminino". Para se alcançar tal objetivo, as feministas propõem a ampliação da fronteira do que é considerado econômico, incorporando todas as mulheres como agentes econômicos e suas atividades, mesmo as que não são remuneradas, como economicamente significativas (MORENO, 2013, p. 26).

$\mathrm{Na}$ economia feminista há duas principais correntes de pensamento. A primeira delas diz respeito à conquista das mulheres pela igualdade que os homens já usufruem:

O objetivo desse modelo seria conseguir a igualdade entre mulheres e homens, mas sem alterar o modelo dominante, ou seja, conseguir que as mulheres se igualassem aos homens em sua forma de participar na sociedade: no mercado de trabalho, nos cargos ou locais de poder, no uso do espaço público [...] (CARRASCO, 2012, p. 36).

Existe, contudo, objeções a respeito da primeira corrente de pensamento. Carrasco (2012, p. 37) argumenta sobre este primeiro modelo ao informar que "a igualdade de direitos pode ser um passo necessário, mas nunca suficiente". 
Pois para a autora a maneira como os homens participam na sociedade depende da existência de alguém dedicado ao trabalho doméstico e de cuidados (que geralmente é feito pelas mulheres). Portanto, para as mulheres chegarem de fato a sua autonomia seria preciso alterar a modelo dominante. Ir além da igualdade de direitos é, portanto, o objetivo da segunda corrente de pensamento:

A segunda corrente propõe que a igualdade de direitos é um passo necessário, mas não suficiente para as transformações da vida das mulheres apresentando, como alternativa, reivindicações que considerem a experiência das próprias mulheres, em vez de partir do que lhes falta para se igualar aos homens (MORENO, 2013, p.54).

Este segundo modelo procura buscar a autonomia das mulheres a partir de suas próprias experiências e não somente almejar alcançar a igualdade entre homens e mulheres. Para Carrasco (2012, p. 37) "trata-se de avançar para a ruptura do modelo masculino, de nomear e dar valor às atividades desenvolvidas tradicionalmente pelas mulheres, [...] de construir um novo mundo simbólico [...]." Seria a construção de um modelo de desenvolvimento humano que rompa com o modelo patriarcal. "Tudo isso com o objetivo da centralidade da vida humana, do bem-estar das pessoas ou, dito de outro modo, da sustentabilidade da vida humana em suas diferentes dimensões e subjetividades" (CARRASCO, 2012, p. 37).

É, por conseguinte, muito mais do que apenas uma maneira de evidenciar e estudar as atividades econômicas das mulheres, mas ir além, construir uma economia com foco no ser humano, sem desconsiderar homens ou mulheres. Uma das maneiras de se alcançar tal propósito é por meio da autonomia econômica das mulheres que é o tema do próximo tópico.

\section{Autonomia econômica das mulheres}

Autonomia econômica é uma reivindicação dos movimentos feministas que busca combater as desigualdades que conduziram as mulheres a se tornarem economicamente aquém dos homens. Moreno (2013, p. 121) diz que "a autonomia econômica é uma das dimensões da capacidade de autodeterminação das pessoas sobre suas próprias vidas, que se soma a outras dimensões, como aquelas relacionadas com o corpo, a sexualidade e a participação política".

No movimento feminista, dois principais movimentos têm em suas pautas a autonomia econômica, que está inexoravelmente ligada ao trabalho: "Trabalho e autonomia econômica constituem, assim, um dos campos de ação da Marcha Mundial das Mulheres e também um eixo permanente da Marcha das Margaridas" (MORENO, 2013, p. 121). Ainda sobre o conceito: 
Autonomia econômica é mais que autonomia financeira. A remuneração não é a única fonte de autonomia; esta depende de nossa formação, do acesso aos bens comuns, ao crédito, à economia solidária e aos serviços públicos. As mulheres produzem riqueza não monetária que é redistribuída diretamente (sem passar pelo sistema financeiro formal): desde pequenas elas dedicam uma grande parte de seu tempo para a satisfação das necessidades da sociedade, dos membros de suas famílias e de suas comunidades (BUTTO et al., 2014, p. 103).

Uma das principais causas das desigualdades econômicas entre homens e mulheres, como visto anteriormente, gira em torno do trabalho doméstico. Fontoura e Gonzalez (2009, p. 24) informam que as desigualdades entre homens e mulheres no mundo do trabalho "[...] se explicam em larga medida pelo fato de que são as mulheres as responsáveis pelo trabalho doméstico relacionado à reprodução das famílias e aos cuidados com as pessoas e a casa". Condição esta ocasionada pela divisão sexual do trabalho. E mesmo quando trabalham fora de casa (trabalho mercantil), a realização do trabalho doméstico dentro de casa ainda é majoritariamente feito por elas, o que acarreta outros problemas como "o desgaste de energias físicas e psíquicas gerados pela dupla jornada manifesta-se atualmente em vários tipos de problemas de saúde na população feminina" (CARRASCO 2012, p. 81). Buscar a autonomia econômica das mulheres é buscar meios de resolver estas questões e:

Isto implica que, entre as reivindicações, para além do direito a uma remuneração digna para seu trabalho, está o acesso aos direitos e serviços públicos que distribuam a responsabilidade com o trabalho doméstico e de cuidados, como políticas de alimentação e cuidados (MORENO, 2013, p 122).

As reivindicações feministas para alcançar a autonomia econômica das muIheres, tais como: a remuneração digna, a distribuição da responsabilidade pela realização do trabalho doméstico e apoio do Estado para a criação de políticas de alimentação e cuidados, parecem ter orientado a elaboração do Plano Nacional de Políticas para as Mulheres (PNPM) de 2013, para os anos de 2014 e 2015, por meio da Secretaria de Políticas para as Mulheres. No plano consta um capítulo intitulado Igualdade no mundo do trabalho e autonomia econômica, que traça como objetivo geral do plano de ações:

Promover a igualdade no mundo do trabalho e a autonomia econômica das mulheres urbanas, do campo e da floresta, considerando as desigualdades entre mulheres 
e homens, as desigualdades de classe, raça e etnia, desenvolvendo ações específicas que contribuam para a eliminação da desigual divisão sexual do trabalho, com ênfase nas políticas de erradicação da pobreza e na valorização da participação das mulheres no desenvolvimento do país (PNPM, 2013, p. 14).

Percebe-se se assim que a reivindicação feminista de autonomia econômica para as mulheres encontra como um meio de ação concreta: a criação de políticas públicas com este fim. No caso, o próprio PNPM (2013, p. 14) diz: "A diminuição da desigualdade reforça a necessidade de políticas específicas dentro do governo federal para a conquista da autonomia econômica das mulheres" e ainda: "Diminuir o tempo das mulheres nos afazeres de casa é tarefa de políticas públicas para a autonomia econômica". Pois, como já vimos, é a divisão sexual do trabalho um dos maiores empecilhos para a conquista da autonomia econômica das mulheres. Vejamos então os objetivos específicos do PNPM 2013-2015:

I. Ampliar a participação e a permanência das mulheres no mundo do trabalho, garantindo a qualidade nas condições e igualdade de rendimentos. II. Promover a organização produtiva e o acesso à renda para mulheres, especialmente das em situação de vulnerabilidade social. III. Promover a valorização e o reconhecimento da contribuição das mulheres do campo, da floresta, mulheres indígenas, das comunidades tradicionais e das mulheres com deficiência para o desenvolvimento econômico do país. IV. Promover políticas que visem o compartilhamento das responsabilidades domésticas e que contribuam para a superação da divisão sexual do trabalho. V. Ampliar a formalização do trabalho das mulheres e a garantia de direitos (PNPM, 2013, p. 14,15).

Vê-se aqui uma das maneiras de busca efetiva da autonomia das mulheres que parte de pautas dos movimentos feministas para se concretizar na forma de políticas públicas realizadas pelo Estado. Apesar de não ser o foco desta pesquisa por limitações de tempo e recursos, essa situação promove a reflexão sobre o real cumprimento desses objetivos e sobre quais resultados na vida das mulheres essas políticas públicas tiveram.

\section{Procedimentos Metodológicos}

\section{Características socioeconômicas de Goiatins-TO}

O município de Goiatins faz parte do Estado do Tocantins e está localizado às margens do rio Manoel Alves Grande, que faz limite com o Estado do Maranhão na porção leste. Segundo dados do Instituto Brasileiro de Geografia e Estatística 
de 2016, a população do município é estimada em 12.813 habitantes e possui uma área de $6.408,602 \mathrm{~km}^{2}$. No Censo Demográfico do IBGE de 2010, a população urbana era composta por 2.436 mulheres e 2.513 homens e a população rural por 3.341 mulheres e 3.774 homens.

Figura 1: Mapa de localização do município de Goiatins (TO)
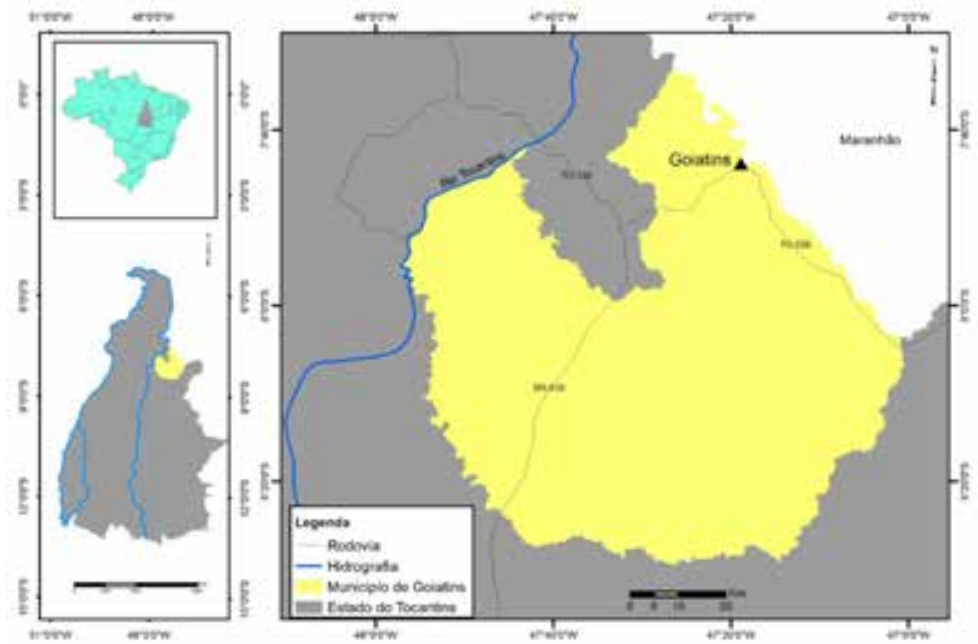

Fonte: Instituto Natureza do Tocantins (NATURATINS) (2017).

Conforme as informações disponíveis no Atlas do Desenvolvimento no Brasil, do Programa das Nações Unidas para o Desenvolvimento - PNUD, (2016), com dados do último Censo (2010), o Índice de Desenvolvimento Humano de Goiatins, que é composto pelas variáveis: renda, longevidade e educação, é de 0,576 . Tal índice é considerado de nível baixo e posiciona o município na $4.718^{a}$ entre os 5.565 municípios do Brasil e na $130^{a}$ posição em relação aos 139 municípios do Estado do Tocantins.

Para o Perfil Socioeconômico dos Municípios feito pelo governo do Estado do Tocantins e publicado em 2015, o Produto Interno Bruto (PIB) total em 2012 foi de R\$ 122.035, 71 e o PIB per capita anual, também em 2012, foi de $\mathrm{R} \$$ 9.986, 56. O rendimento domiciliar per capita (IBGE, 2010), consta que aproximadamente $58 \%$ dos indivíduos ganham até meio salário mínimo, $22 \%$ de meio a 1 salário mínimo, $14 \%$ de 1 a 2 salários mínimos, $5 \%$ de 2 a 5 salários mínimos e $1 \%$ mais de 5 salários mínimos.

O Atlas do Desenvolvimento no Brasil (2016) informa que 37,47\% dos indivíduos eram extremamente pobres e $53,72 \%$ eram pobres. A composição da população com mais de 18 anos, se caracterizava por $51,8 \%$ da população econo- 
micamente ativa ocupada, $6,4 \%$ da população economicamente ativa desocupada e $41,8 \%$ da população economicamente inativa, porém a porcentagem de formalização do total da população economicamente ativa ocupada era de $26,90 \%$. O quesito educação adulta, do Atlas do Desenvolvimento no Brasil, aponta que a população de 25 anos ou mais, em 2010 , era composta por $32,3 \%$ indivíduos com ensino fundamental incompleto e analfabeto, $39 \%$ com ensino fundamental incompleto e alfabetizado, 9,8\% com ensino fundamental completo e ensino médio incompleto, $13,6 \%$ com ensino médio completo e superior incompleto e, $5,3 \%$ com o ensino superior completo.

Outros dados curiosos sobre a vulnerabilidade social do município encontrado no Atlas do Desenvolvimento no Brasil (2016) são os de que: $24,61 \%$ das mães chefes de família não tinham o ensino fundamental e com filho menor; $71,93 \%$ das pessoas eram vulneráveis à pobreza e $64,14 \%$ das pessoas com 18 anos ou mais não tinham completado o ensino fundamental e estavam em ocupações informais.

\section{Tipo de pesquisa e método de coleta de dados}

A pesquisa deste trabalho é descritiva e exploratória, o que para Gil (2008), serve para descrever as particularidades de determinadas populações ou fenômenos, usando técnicas padrões de coletas de dados como, por exemplo, o questionário e para construir hipóteses ou se familiarizar com determinado problema para explicá-lo melhor por ainda ser pouco conhecido.

O objeto de estudo deste trabalho são as mulheres residentes na área urbana da cidade de Goiatins, no Estado do Tocantins, em particular, as mulheres adultas e chefes de familia. A delimitação da amostra se deu pelas 1.296 famílias (IBGE, 2010) que vivem na zona urbana.

A coleta de dados ocorreu por meio da aplicação de um questionário semiestruturado com questões abertas e fechadas do dia 14 a 20 de outubro de 2016, período escolhido pela disponibilidade de recursos humanos e financeiros para a realização da pesquisa, por acessibilidade e esgotamento. Foi escolhida aleatoriamente uma mulher de diferentes setores da cidade para variar a área da pesquisa. Cada mulher entrevistada indicava a próxima a ser entrevistada que por sua vez indicava outra e assim sucessivamente.

O questionário foi aplicado a 55 mulheres e no momento de sua aplicação era lido inicialmente por uma das pesquisadoras à participante, que em seguida respondia oralmente as perguntas. As respostas eram transcritas imediatamente de forma manuscrita no questionário pela entrevistadora.

Os dados foram analisados de forma descritiva e quantitativa. Tendo sido usado o programa Microsoft Excel, para as fórmulas matemáticas, como média e porcentagem, e para a elaboração dos gráficos. 


\section{Resultados e Discussões}

\section{O perfil socioeconômico das mulheres de Goiatins}

Para as residências visitadas, cada uma possuia em média quatro pessoas, sendo que o maior número de pessoas encontradas nesssas residências foi o de nove moradores e o menor número um morador. Pelo levantamento da quantidade de indivíduos morando na residência de cada uma das 55 mulheres que responderam o questionário, foi possivel inferir que no total havia 227 pessoas em tais residências, existindo uma média de quatro pessoas por casa.

A idade média das mulheres entrevistadas é de 44 anos, tendo a mais nova 21 anos e a mais velha 79 anos. Em relação ao estado civil, 25 delas são casadas, 20 solteiras, 6 são viúvas e 4 exibem união estável.

A renda média dessas mulheres é de aproximadamente $R \$ 724,47$ mensais, sendo a menor renda de $\mathrm{R} \$ 163,00$ e a maior renda de $\mathrm{R} \$ 3.000,00$. Cinco mulheres afirmaram não ganhar nenhuma renda e três não souberam responder. E a renda média total das famílias, solicitada no questionário, é de $\mathrm{R} \$ 1.784,93$ (dez respondentes não sabiam informar o valor).

No gráfico 1 é apresentado o nível educacional das mulheres de Goiatins.

Gráfico 1: Nivel Educacional

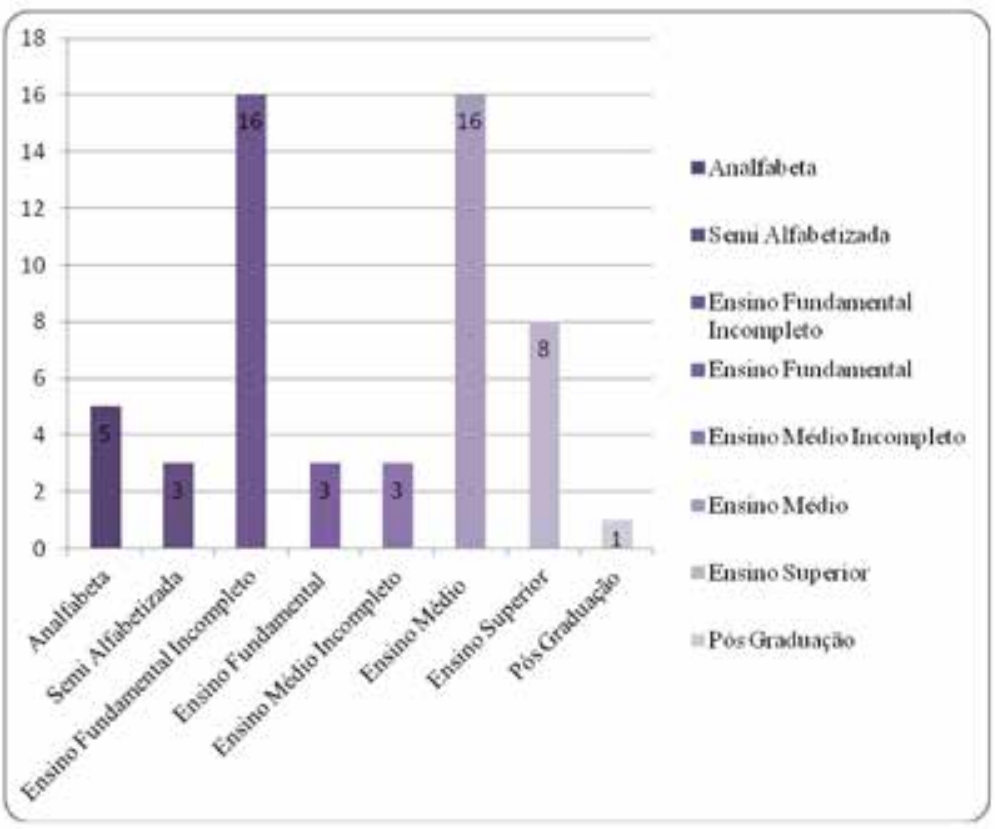

Fonte: Elaborado pela autora com base nos dados da pesquisa (2016). 
O gráfico 1 representa números absolutos (unidades de pessoas) composto pelas 55 mulheres e seus graus de estudo. Destas, apenas dezesseis concluíram o ensino médio, oito têm o ensino superior e apenas uma é pós-graduada. Segundo o Atlas do Desenvolvimento no Brasil (2016), da população adulta do município, $18,93 \%$ possuía o ensino médio completo e apenas $5,32 \%$ o superior completo. Chama atenção, por exemplo, o fato de dezesseis mulheres terem apenas o ensino fundamental incompleto.

\section{A composição das fontes de sustento e sobrevivência das mulheres de Goiatins}

Durante a composição do questionário as autoras procuraram identificar as atividades monetárias e as não monetárias, realizadas pelas mulheres, de modo a contemplar a abordagem da economia feminista. Foram detectadas 11 categorias de trabalho monetárias e quatro tipos de benefícios sociais. As informações estão apresentadas na Tabela 1.

Tabela 1: Categorias de atividades realizadas pelas mulheres de Goiatins (TO) e os benefícios monetários recebidos

\section{Categorias de trabalho}

Trabalho Formal no Comércio

Trabalho Informal

Serviço Público

Negócio Próprio Formal

Negócio Próprio Informal

Autônoma

Produção de Alimentos

Produção de Artesanato

Coleta de Frutos

Plantação

Criação de Animais

Beneficios Sociais
Trabalho realizado

Atendente de caixa.

Serviço doméstico, assessoria, cuidado de crianças.

Merendeiras, secretária, auxiliar de serviços gerais, professora, enfermeiras, pedagoga, assistente social e recepcionista.

Comércio.

Comércio e serviços de beleza.

Revendedoras de cosméticos e revendedora de doce.

Geladinha, bombons caseiros, água de coco.

Crochê, corte e costura.

Derivados de frutas tipicas: buriti, etc.

Comestiveis: cebolinha e coentro.

Galinhas.

Bolsa-familia, aposentadoria, pensão por morte e auxíliodoença.

Fonte: elaborado pela autora com base nos dados da pesquisa (2016).

No gráfico 2 estão distribuídas as porcentagens de atividades realizadas pelas mulheres e os benefícios recebidos. 
Gráfico 2: Composição das atividades e benefícios monetários

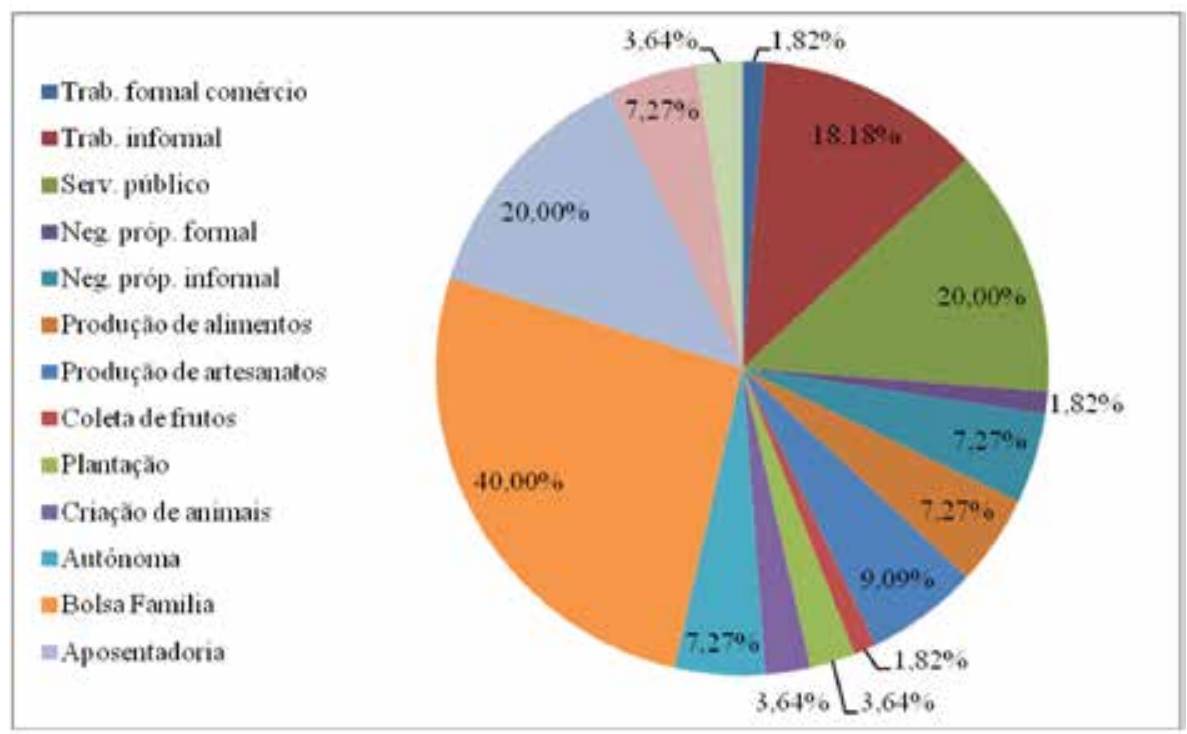

Fonte: elaborado pela autora com base nos dados da pesquisa (2016).

É importante frisar que algumas mulheres entrevistadas executam mais de uma atividade ou, por exemplo, trabalham e recebem algum beneficio social e que, portanto, há mais de cem por cento na representação gráfica.

Por meio do gráfico 2, é possivel identificar que $32,72 \%$ das mulheres estão em situação de informalidade, considerando a soma do trabalho informal, do negócio próprio informal e do trabalho autônomo. Além disso, 19 das 55 muIheres entrevistadas realizam esporadicamente ou não a venda de alimentos, artesanatos, frutos, hortaliças e animais; sendo que tais itens são coletados, produzidos ou criados por elas mesmas.

É oportuno neste momento, relembrar que, segundo o Atlas do Desenvolvimento Humano no Brasil (2016) para o município de Goiatins, 71,93\% das pessoas são vulneráveis à pobreza e $64,14 \%$ das pessoas com 18 anos ou mais completou o ensino fundamental e estavam em ocupações informais. Os dados apresentados no gráfico 2 podem contribuir no entendimento de que $40 \%$ das mulheres recebam bolsa-família como um mecanismo de auxilio na renda. Estando $23,64 \%$ delas na formalidade (trabalho formal comércio, serviço público e negócio próprio formal).

$\mathrm{Na}$ Tabela 2 estão apresentados os quatro tipos de atividades que contribuiam para a sobrevivência das mulheres e de seus familiares, mas não de forma monetária e sim como forma de sustento e uso de itens criados, cultivados ou produzidos por elas mesmas. 
Tabela 2: Tipos de atividades não monetárias realizadas pelas mulheres de Goiatins (TO)

\begin{tabular}{cc} 
Atividades & Descrição das atividades \\
\hline Produção de Artesanato & Crochê, corte e costura, confeç̧ão de objetos e personalização. \\
Coleta de Frutos & Manga, caju, buriti, cajá e outros frutos típicos do local. \\
Plantação & $\begin{array}{c}\text { Comestiveis: coentro, cebolinha, alface, feijão, pimenta, } \\
\text { mandioca, etc. Medicinais: erva-cidreira, boldo, hortelã, capim } \\
\text { de cheiro e outras. }\end{array}$ \\
Criação de animais & Predominio de galinha, e com menos frequência os porcos. \\
\hline
\end{tabular}

Fonte: elaborado pela autora com base nos dados da pesquisa (2016).

No gráfico 3 está apresentado a porcentagem das atividades realizadas pelas mulheres como forma de sustento.

Gráfico 3: Composição das atividades não monetárias

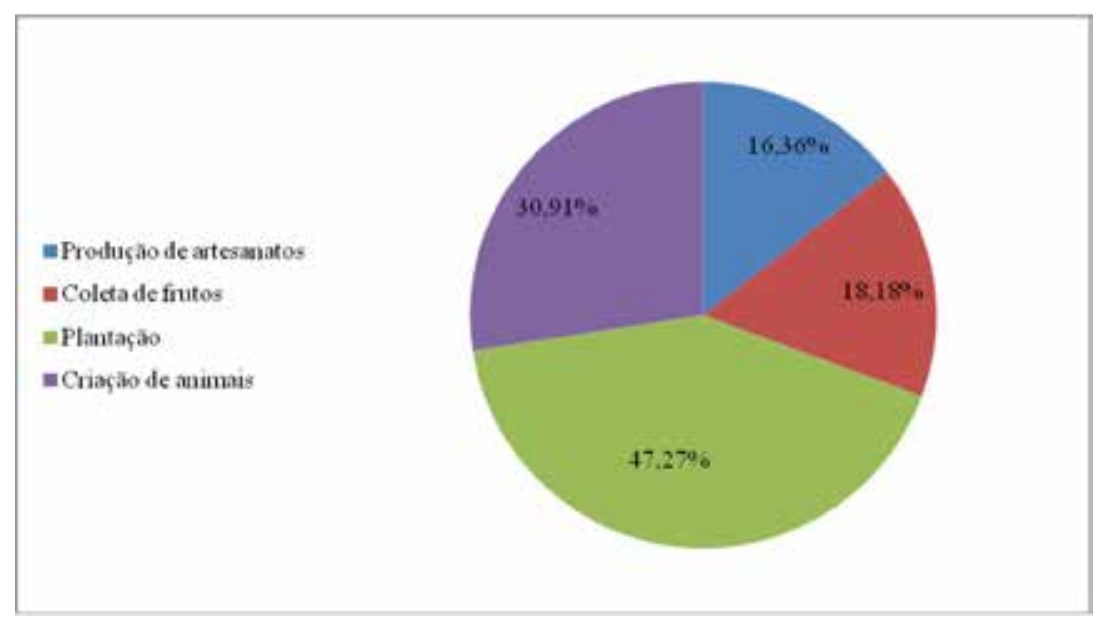

Fonte: elaborado pela autora com base nos dados da pesquisa (2016).

Como se pode observar, uma parte considerável das mulheres se dedica às atividades não monetárias. Tais atividades garantem o uso e o consumo de produtos e alimentos de forma autossustentável, garantindo a satisfação das necessidades básicas, pois aquilo que é consumido pelas mulheres e suas famílias não é comprado e sim produzido, criado ou coletado por elas a custo de seu tempo.

A média de horas gastas com as atividades monetárias e não monetárias foi de aproximadamente 5 horas por dia, sendo que o mínimo de dedicação apresentado foi de 30 minutos e o máximo de 14 horas. Das mulheres entrevistadas, 11 delas não souberam responder a quantidade de tempo que dedicam a tais atividades. 


\section{O trabalho desconsiderado}

Na categoria de inativos, segundo os censos demográficos, está incluso aqueles que só fazem afazeres domésticos, pois estas não são consideradas atividades econômicas e tampouco trabalho (BRUSCHINI, 2006, p. 333). O IBGE (2013), por exemplo, caracteriza como afazeres domésticos, tanto o cuidado com a casa quanto o cuidado com as pessoas.

Para a economia feminista são trabalhos distintos, o trabalho doméstico seria o cuidado com a casa: lavar roupas, limpar, cozinhar; e o trabalho de cuidados seria o cuidado com pessoas: crianças, idosos e dependentes. "Conferir visibilidade ao trabalho doméstico e de cuidados na análise econômica é uma questão central para a economia feminista, uma vez que a reprodução da força de trabalho depende dele" (MORENO, 2013, p. 29).

Para a economia feminista o trabalho doméstico e de cuidados apesar de não ser remunerado, gera riqueza para a sociedade e sem ele não seria possivel o funcionamento do sistema econômico como está posto hoje, pois as pessoas têm necessidades que ou o mercado não fornece ou elas não têm condições de conseguir com suas rendas, como por exemplo, os primeiros cuidados durante a infância ou os cuidados durante a velhice, e majoritariamente são as mulheres que realizam estes trabalhos. Na Tabela 3 é apresentada a porcentagem de mulheres e o número de horas que elas se dedicam para cada um dos trabalhos.

Tabela 3: Trabalho doméstico e de cuidados realizados pelas mulheres de Goiatins (TO)

\begin{tabular}{cccc} 
Atividade & Porcentagem & $\begin{array}{c}\text { Média de } \\
\text { horas/dia }\end{array}$ & $\begin{array}{c}\text { Mínimo e Máximo de } \\
\text { horas/dia }\end{array}$ \\
\hline Trabalho de cuidados & 31 mulheres ou $56,36 \%$ & $3 \mathrm{~h}$ & $30 \mathrm{~min} / 15 \mathrm{horas}$ \\
Trabalho doméstico & 53 mulheres ou $96,36 \%$ & $6 \mathrm{~h}$ & $20 \mathrm{~min} / 12 \mathrm{horas}$ \\
\hline
\end{tabular}

Fonte: elaborado pela autora com base nos dados da pesquisa (2016).

Apenas duas mulheres não fazem o trabalho doméstico, uma porque é deficiente fisica e a outra porque tem a maior renda das 55 e, afirmou ter condições de contratar os serviços de outra mulher. No processo de estimar as horas gastas com o trabalho doméstico e de cuidados não remunerado, foi constante o uso de expressões para definir o tempo gasto como: "o dia todo" e "constante". No entanto, é necessário esclarecer que o trabalho constante ou que leva o dia todo, segundo as entrevistadas, não é ininterrupto, ou seja, existem pausas para o seu desenvolvimento ao longo do dia ou mesmo quando leva parte da noite e que, pelo observado e pelas respostas das mulheres, o trabalho de cuidados e o trabalho doméstico são feitos, muitas vezes, de forma simultânea. 
A média de horas semanais gastas com afazeres domésticos no Estado do Tocantins segundo a PNAD (2015) é de 11,7 horas para homens e 24,3 horas para as mulheres, ou seja, as mulheres trabalham 12,6 horas a mais.

\section{Cuidar da saúde da gente}

Uma das questões abertas questionava o que o poder público poderia fazer para facilitar o dia a dia das mulheres. As respostas estão apresentadas no gráfico 4 na forma de tópicos.

Gráfico 4: Necessidades socioeconômicas apresentadas pelas mulheres de Goiatins (TO)

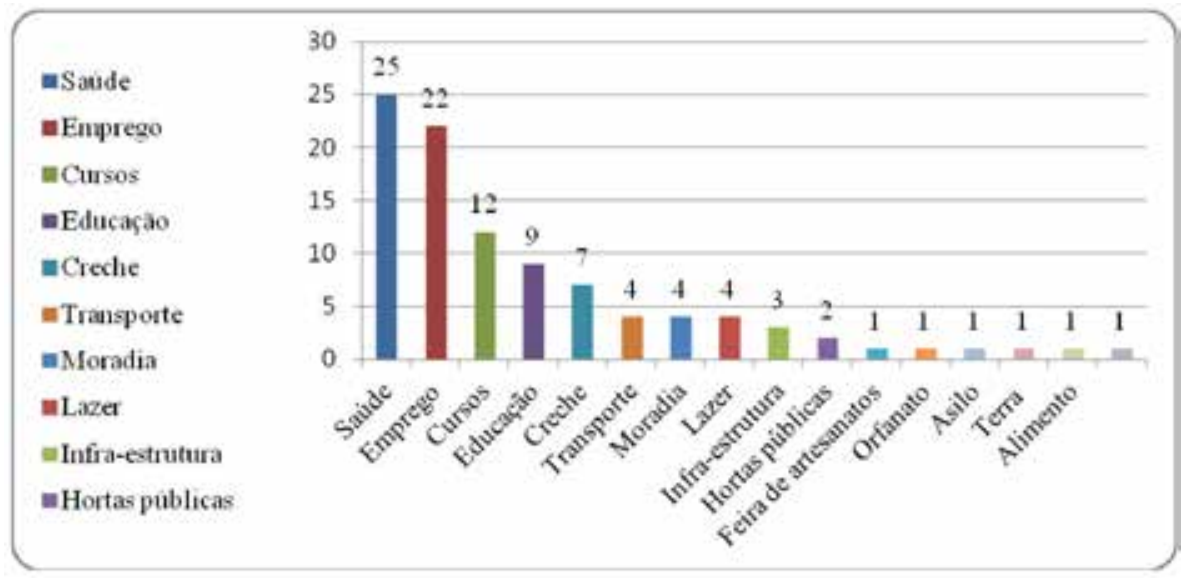

Fonte: elaborado pela autora com base nos dados da pesquisa (2016).

As colunas no gráfico 4 representam números absolutos por pessoa. As entrevistadas além de apontarem as necessidades socioeconômicas, especificaram - que seria essencial para elas no momento da entrevista. Conforme o gráfico 4, as cinco necessidades mais expressivas foram: Saúde: presença de médicos especialistas e medicamentos gratuitos, atendimento ao idoso, posto de saúde próximo de suas residências e uma queria trocar a cadeira de rodas; Emprego: sete entrevistadas disseram que havia necessidade de fábricas ou empresas que pudessem gerar empregos para elas ou principalmente para os filhos e uma delas gostaria que o trabalho das mulheres fosse mais valorizado; Cursos: uma entrevistada sugeriu a presença de uma faculdade, quatro mulheres apontaram a necessidade de cursos profissionalizantes para elas ou para os jovens, cinco informaram que gostariam que se ofertasse curso de artesanato "voltados para donas de casa" e duas delas apontaram a oferta de cursos e atividades extracurriculares nas escolas; Educação: três entrevistadas solicitaram escolas integrais, uma queria escola 
próxima a residência e duas mulheres apontaram a necessidade de escolas meIhores; Creches: sete entrevistadas gostariam de um lugar pra deixar as crianças. Apenas duas, das cinquenta e cinco mulheres, não responderam a esta questão.

A segunda questão aberta presente no roteiro do questionário foi: Aonde as mulheres gostariam de trabalhar se pudessem escolher e o que as impedia de fazer isto. As respostas estão na Tabela 4.

Tabela 4: Locais de trabalho desejados pelas mulheres de Goiatins (TO) e os impedimentos para efetuá-los

Aonde trabalharia?

Impedimentos

Artesanato

Falta de incentivos, de cursos e/ou feiras.

Profissão com necessidade de

Ensino Superior

Ausência de universidade pública.

Serviço Público

Careciam de oportunidades.

Serviço Doméstico

Não ter com quem deixar as crianças ou ausência de outras oportunidade.

Cultivo da terra

Ausência de terra.

Fonte: elaborado pela autora com base nos dados da pesquisa (2016).

Das 55 mulheres entrevistadas, sete delas se disseram satisfeitas e oito não responderam. Algumas das mulheres que não responderam eram idosas e por isto não se consideravam aptas para a execução de algum tipo de trabalho, uma das entrevistadas era deficiente física e outra mulher, ainda jovem, disse não poder sair de casa por ter que cuidar da filha com deficiência física e mental.

Para as demais entrevistadas são apresentadas as respostas de forma detaIhada. Nove mulheres gostariam de trabalhar com artesanato e não o faziam por falta de incentivos como feiras públicas e fábricas; oito delas queriam trabalhar em profissões que requeriam o ensino superior, como por exemplo, ser administradora ou médica, e a ausência de uma universidade pública na cidade impediria a concretização da profissão; quatro mulheres gostariam de trabalhar no serviço público, sendo secretária, por exemplo, e para isso careciam de oportunidade, como um concurso público; quatro entrevistadas trabalhariam no serviço doméstico e não o faziam por não ter com quem deixar as crianças ou por falta de oportunidade; três mulheres cultivariam a terra e criariam animais, se tivessem a posse da terra; outras respostas menos frequentes incluíram: culinária, escritora, cabeleireira, recepcionista, etc. 
Por meio das respostas apresentadas foi possivel identificar alguns fatores que limitam a autonomia econômica das mulheres de Goiatins (TO), entre eles estão: a precariedade da saúde, a ausência de trabalho, a carência de cursos profissionalizantes, de ensino superior, precariedade na educação para os filhos, falta de creches e de políticas públicas que dialoguem com suas realidades sociais e econômicas.

Outro fator limitante é o tempo que as mulheres entrevistadas despendem com o trabalho doméstico e o de cuidados, que em média é 6 e 3 horas por dia, respectivamente. O Plano Nacional de Políticas para as Mulheres (2013, p. 14) menciona que uma maneira de garantir a autonomia econômica e a igualdade entre homens e mulheres no mundo do trabalho é por meio de "[...] ações específicas que visam a eliminação da desigual divisão sexual do trabalho, com ênfase na erradicação da pobreza e na garantia de participação das mulheres no desenvolvimento do Brasil". É dar a elas, a possibilidade de escolher os caminhos de suas vidas.

\section{Considerações Finais}

A pesquisa desenvolvida procurou identificar e descrever as condições socioeconômicas de uma parcela das mulheres chefes de família residentes na cidade de Goiatins (TO), constituindo o primeiro relato formal da situação vivenciada por elas. $O$ estudo permitiu também que tais mulheres pudessem apontar possiveis mecanismos de auxilio na sua renda e os problemas enfrentados por elas para alcançarem uma autonomia econômica. Dessa forma, os principais resultados obtidos estão apresentados nos parágrafos subsequentes.

As fontes de sobrevivência e sustento monetário das mulheres de Goiatins (TO) são compostas por onze tipos de atividades e quatro tipos de benefícios sociais. Para as 55 entrevistadas, as fontes de sobrevivência estão distribuídas entre trabalhos formais (23,64\%); trabalhos informais (32,72\%), e produção (alimento ou artesanato), coleta de alimentos ou criação de animais que são usados para consumo próprio e venda $(25,46 \%)$. Em relação aos benefícios, esses estão distribuídos em bolsa-família (40\%), aposentadoria (20\%), pensão por morte $(7,27 \%)$ e auxílio-doença (3,64\%). Esta é a composição da renda monetária e sua separação entre formal e informal.

Além da renda monetária, foram detectadas quatro atividades não monetárias que contribuem com o sustento da vida, na medida em que coloca à disposição das mulheres e de suas famílias, objetos e alimentos para uso e consumo, que são produzidos por elas e não comprados. As atividades estão distribuídas na confecção de artesanato (16,36\%), coleta de frutos típicos da região (18,18\%), plantio (47,27\%), e criação de animais (30,91\%).

O tempo médio dedicado ao trabalho monetário e não monetário foi de aproximadamente 5 horas por dia. $\bigcirc$ tempo médio dedicado ao trabalho doméstico foi de 6 horas por dia, para 53 das 55 mulheres entrevistadas, embora algumas 
(14) tenham dito trabalhar 10 horas ou mais por dia. Para o trabalho de cuidados, o tempo médio empregado foi de 3 horas por dia, para 31 entrevistadas, havendo, porém, algumas mulheres que afirmaram trabalhar 10 horas ou mais por dia. Os resultados confirmam a maneira como a divisão sexual do trabalho responsabiliza as mulheres pelo trabalho reprodutivo.

A contribuição das mulheres para o sustento de suas famílias ocorre por meio da renda média monetária de $\mathrm{R} \$ 724,47$ que possuem por meio da execução de trabalhos remunerados; pelas atividades não monetárias que garantem o uso e o consumo de objetos e alimentos; e ainda pelo trabalho doméstico e o trabaIho de cuidados que elas realizam de forma gratuita para suas famílias, que têm necessidades humanas ou que não são vendidas no mercado ou não podem ser adquiridas por falta de recursos financeiros.

As entrevistadas identificaram também os fatores que influenciavam a autonomia econômica das mulheres em Goiatins. Eles estão atrelados com: a precariedade da saúde e do trabalho, a falta educação de qualidade para os filhos, a ausência de cursos profissionalizantes e de ensino superior, carência de creches, de lazer e de incentivo ao artesanato. Adicionalmente, as grandes cargas horárias dedicadas ao trabalho doméstico e de cuidados impedem o desenvolvimento de outras atividades. Observa-se que os apontamentos mencionados pelas mulheres extrapolam a individualidade, e recaem em um plano maior, isto é, para atender a sociedade, e isso é expresso quando as entrevistadas almejam emprego para os jovens e melhor infraestrutura na cidade.

A renda média mensal de $\mathrm{R} \$ 724,47$ e a deficiência de recursos básicos para a qualidade de vida apresentadas pelas entrevistadas é um recorte dos dados que sustentam as informações socioeconômicas contidas no Atlas do Desenvolvimento Humano no Brasil (2016) para o município de Goiatins (TO).

Considerando que a economia feminista se coloca como proposta de construção de uma teoria diferente da economia tradicional e como uma economia que "centra seu objetivo na vida humana, no bem-estar das pessoas, nos modos de vida - em resumo, na sustentabilidade da vida humana em suas diferentes dimensões e subjetividades" (CARRASCO, 2012, p. 96), consideramos que é necessário maior empenho nas esferas municipal, estadual e federal para o desenvolvimento do município, para a criação de políticas públicas voltadas para as mulheres e que Ihes auxiliem na conquista da autonomia econômica, em uma divisão do trabalho doméstico e de cuidados mais igualitária que pode ser amenizada pela construção de creches, de restaurantes públicos, de lavanderias públicas, de abrigo para idosos e serviços públicos de cuidados para pessoas com deficiências físicas e/ou mentais, além da necessidade de lhes assegurar os direitos básicos de educação (de gênero também), saúde, trabalho, habitação, alimentação, transporte, etc.

Como sugestão, recomenda-se a extensão desta pesquisa às mulheres da 
zona rural do município de Goiatins, o estudo de políticas públicas do estado que incentive a autonomia econômica das mulheres, no estado ou município, e/ou a comparação entre a carga horária que as mulheres do município dedicam ao trabalho doméstico e de cuidados com as horas que os homens dedicam a estes mesmos trabalhos.

\section{Referências}

ATLAS DO DESENVOLVIMENTO HUMANO NO BRASIL. Goiatins To. 2016. Disponivel em < http://atlasbrasil.org.br/2013/pt/perfil_m/goiatins_to>. Acesso em: 05/05/16.

BRASIL. Secretaria de Políticas para as Mulheres. Plano Nacional de Políticas para as Mulheres. Brasilia: Secretaria de Políticas para as Mulheres, 2013.

BARBOSA, R. N. C. A economia solidária como política pública: uma tendência de geração de renda e ressignificação do trabalho no Brasil. São Paulo: Editora Cortez, 2007.

BRUSCHINI, C. Trabalho doméstico: inatividade econômica ou trabalho não-remunerado? Revista Brasileira de Estudos de População. São Paulo, v. 23, n. 2, 2006.

BUTTO, A.; DANTAS, C.; HORA, K.; NOBRE, M.; FARIA, N. (org.) Mulheres rurais e autonomia: formação e articulação para efetivar políticas públicas nos territórios da cidadania. Brasília: Ministério do Desenvolvimento Agrário, 2014.

CARRASCO, C. Estatísticas sob suspeita: proposta de novos indicadores com base na experiência das mulheres. Tradução José Valenzuela Perez. São Paulo: SOF Sempre Viva Organização Feminista, 2012.

FONTOURA, N. O.; GONZALEZ, R.. Aumento da participação de mulheres no mercado de trabalho: mudança ou reprodução da desigualdade? IPEA: mercado de trabalho, 2009.

GIL, A. C. Como elaborar projetos de pesquisa. 4. ed. São Paulo: Atlas, 2008. GUÉRIN, I. As mulheres e a economia solidária (2005), tradução: Nicolás Nyimi Campanário - Título original: Femmes ET économiesolidaire, Paris 2003.

HIRATA, Helena; LABORIE, Françoise; DOARÉ, Hélène Le; SENOTIER; Danièle (org.). Dicionário crítico do feminismo. São Paulo: Editora UNESP, 2009.

IBGE, Coordenação de Trabalho e Rendimento. Pesquisa nacional por amostra de domicilios: síntese de indicadores 2013. 2. Ed. Rio de Janeiro: IBGE, 2015. IBGE. Censo Demográfico. Rio de Janeiro: IBGE, 2010. 
IBGE, TSE. O seu Município em Números 2016, 2016.

IBGE. Sintese de indicadores sociais: Uma análise das condições de vida, 2013.

MORENO, R. F. C. Além do que Se Vê, Uma Leitura das Contribuições do Feminismo Para a Economia. Dissertação (Mestrado em Ciências Humanas e Sociais) UFABC - Universidade Federal do ABC, 2013.

PROGRAMA DAS NAÇÕES UNIDAS PARA O DESENVOLVIMENTO. Atlas do Desenvolvimento Humano no Brasil, 2016. Disponivel em <http:// www.atlasbrasil.org.br/2013/pt/perfil_m/filadelfia_to >. Acesso em: 10/05/16.

QUINTELA, S. Economia Feminista e Economia Solidária: sinais de outra economia. Rio de Janeiro, PACS - Instituto Políticas Alternativas para o Cone Sul, 2006.

SABBATO, A. Di; MELO, H. P.; LOMBARDI, M. R.; FARIA, N. Organização de Andrea Butto. Estatísticas rurais e a economia feminista: um olhar sobre o trabalho das mulheres. Brasilia: MDA, 2009.

SECRETARIA DO PLANEJAMENTO E ORÇAMENTO: Governo do Tocantins. Perfil Socioeconômico dos Municípios: Goiatins, 2015.

Recebido em janeiro de 2019

Aprovado em maio de 2019. 